\title{
A multiple-outgroup approach to resolving division-level phylogenetic relationships using 165 rDNA data
}

\author{
Daniel Dalevi, ${ }^{1}$ Philip Hugenholtz ${ }^{2}$ and Linda L. Blackall ${ }^{2}$
}

Author for correspondence: Linda L. Blackall. Tel: +61 73365 4645. Fax: +61 733654620.

e-mail: blackall@biosci.uq.edu.au

1 Department of Molecular Evolution, University of Uppsala, Box 590, S-751 24, Uppsala, Sweden

2 Advanced Wastewater Management Centre, Department of Microbiology and Parasitology, The University of Queensland, Brisbane, Queensland 4072, Australia

\begin{abstract}
The 165 rRNA gene (16S rDNA) is currently the most widely used gene for estimating the evolutionary history of prokaryotes. To date, there are more than $3000016 \mathrm{~S}$ rDNA sequences available from the core databases, GenBank, EMBL and DDBJ. This great number may cause a dilemma when composing datasets for phylogenetic analysis, since the choice and number of reference organisms are known to affect the resulting tree topology. A group of sequences appearing monophyletic in one dataset may not be so in another. This can be especially problematic when establishing the relationships of distantly related sequences at the division (phylum) level. In this study, a multiple-outgroup approach to resolving division-level phylogenetic relationships is suggested using 165 rDNA data. The approach is illustrated by two case studies concerning the monophyly of two recently proposed bacterial divisions, OP9 and OP10.
\end{abstract}

Keywords: $16 \mathrm{~S}$ rRNA, phylogenetic inference, bacterial divisions, outgroup artefacts

\section{INTRODUCTION}

rRNA genes (rDNA) have been used to construct a universal phylogeny for all forms of cellular life: the tree of life (Woese, 1987). Protein-encoding genes are also widely used for inferring phylogenies. These frequently contradict rRNA phylogenies, because of lateral gene transfer and/or limitations in the phylogenetic analysis (Doolittle, 1999; Pennisi, 1998). The latter may result from lack of available reference data (outgroups), inadequate analysis of the available data or insufficient phylogenetic signal in the data to resolve the relationships of interest (Smith, 1994; Woese, 1987).

Protein-encoding gene datasets are often limited by the lack of available outgroup sequences for the gene of interest; however, for 16S rDNA, there are today more than 30000 sequences available from the core databases GenBank (Benson et al., 1999), EMBL (Stoesser et al., 1999) and DDBJ (Sugawara et al., 1999), providing an ample supply of outgroup sequences for most comparative analyses. Studies of $16 \mathrm{~S}$ rRNA

Abbreviations: $\mathrm{BP}$, bootstrap proportion; ED, evolutionary-distance; GTR, general time-reversible; LBA, long-branch attraction; ML, maximumlikelihood; MP, maximum-parsimony. genes amplified directly by PCR from environmental samples have contributed significantly to this abundant supply of sequences and indicate that many unrecognized major microbial lineages exist in nature, with greater phylogenetic depth than the plants, animals and fungi combined (Hugenholtz et al., 1998b).

The lack of, or inappropriate selection of, outgroup sequences for phylogenetic analyses can result in misleading conclusions about the monophyly of the ingroup (comprising the taxa of primary interest) (Adachi \& Hasegawa, 1995; Smith, 1994; Stackebrandt \& Ludwig, 1994). The best approach to avoid this problem is to include a large number of outgroups (Hillis, 1996) and to use an inference method that describes the process of evolution relatively accurately, such as rate-corrected maximumlikelihood (ML) (Yang, 1994). However, ML methods can only be applied to relatively small datasets (typically $<50$ taxa) due to current computation limitations, restricting the number of outgroups that can be used in any one analysis.

Here, we suggest an approach to test the hypothesis of monophyly of an ingroup by using multiple sets of outgroup sequences. Two case studies are presented to illustrate the idea. They concern the monophyly of two 
Table 1 Composition of the datasets used in the two case studies

\begin{tabular}{|c|c|c|c|c|c|c|c|c|c|c|c|}
\hline \multirow[t]{2}{*}{ Bacterial division* } & \multirow[t]{2}{*}{ Taxon } & \multicolumn{2}{|c|}{ 16S rRNA sequence } & \multicolumn{8}{|c|}{ Dataset $\dagger$} \\
\hline & & Accession no. & $\begin{array}{l}\text { Length } \\
\text { (nt) }\end{array}$ & OP10A & OP10B & OP10C & OP9A & OP9A2 & OP9B & OP9C & OP9C2 \\
\hline \multirow[t]{2}{*}{ OP10 } & Hot-spring clone OPB50 & AF027092 & 1441 & $\mathrm{x}$ & $\mathrm{x}$ & $\mathrm{x}$ & & & & & \\
\hline & Hot-spring clone OPB 80 & AF027089 & 1450 & $\mathrm{x}$ & $\mathrm{x}$ & $\mathrm{x}$ & & & & & \\
\hline \multirow[t]{3}{*}{ OP9 } & Hot-spring clone OPB47 & AF027082 & 1502 & & & & $\mathrm{x}$ & $\mathrm{x}$ & $\mathrm{x}$ & $\mathrm{x}$ & $\mathrm{x}$ \\
\hline & Hot-spring clone OPB72 & AF027086 & 1255 & & & & $\mathrm{x}$ & $\mathrm{x}$ & $\mathrm{x}$ & $\mathrm{x}$ & $\mathrm{x}$ \\
\hline & $\begin{array}{l}\text { Thermophilic UASB } \\
\text { granule clone TUG14 }\end{array}$ & AB011342 & 619 & & & & $\mathrm{x}$ & $\mathrm{x}$ & $\mathrm{x}$ & $\mathrm{x}$ & $\mathrm{x}$ \\
\hline \multirow{3}{*}{ OP10-like } & Sludge clone SBR 1039 & $\mathrm{X} 84482$ & 1436 & $\mathrm{x}$ & $\mathrm{x}$ & $\mathrm{x}$ & & & & & \\
\hline & Sludge clone $\mathrm{CH} 21$ & AJ271047 & 1433 & $\mathrm{x}$ & $\mathrm{x}$ & $\mathrm{x}$ & & & & & \\
\hline & Sludge clone GC55 & AJ271048 & 1431 & $\mathrm{x}$ & $\mathrm{x}$ & $\mathrm{x}$ & & & & & \\
\hline \multirow[t]{4}{*}{ OP9-like } & $\begin{array}{l}\text { Benzene-mineralizing } \\
\text { consortium clone SB-15 }\end{array}$ & AF029043 & 1527 & & & & $\mathrm{x}$ & $\mathrm{x}$ & $\mathrm{x}$ & $\mathrm{x}$ & $\mathrm{x}$ \\
\hline & $\begin{array}{l}\text { Benzene-mineralizing } \\
\text { consortium clone SB-45 }\end{array}$ & AF029050 & 1527 & & & & $\mathrm{x}$ & $\mathrm{x}$ & $\mathrm{x}$ & $\mathrm{x}$ & $\mathrm{x}$ \\
\hline & $\begin{array}{l}\text { Deep-sea sediment clone } \\
\text { JTB138 }\end{array}$ & АВ015269 & 1608 & & & & $\mathrm{x}$ & $\mathrm{x}$ & $\mathrm{x}$ & $\mathrm{x}$ & $\mathrm{x}$ \\
\hline & $\begin{array}{l}\text { Deep-sea sediment clone } \\
\text { JTB243 }\end{array}$ & АB015271 & 1548 & & & & $\mathrm{x}$ & $\mathrm{x}$ & $\mathrm{x}$ & $\mathrm{x}$ & $\mathrm{x}$ \\
\hline \multirow[t]{3}{*}{ Proteobacteria } & Agrobacterium tumefaciens & M11223 & 1489 & $\mathrm{x}$ & & & $\mathrm{x}$ & $\mathrm{x}$ & & & \\
\hline & Rhodocyclus purpureus & M34132 & 1471 & $\mathrm{x}$ & & & $\mathrm{x}$ & $\mathrm{x}$ & & & \\
\hline & Escherichia coli & J01695 & 1542 & $\mathrm{x}$ & & & $\mathrm{x}$ & $\mathrm{x}$ & & & \\
\hline \multirow[t]{3}{*}{ Flexistipes } & Flexistipes sinusarabici & M159231 & 1473 & $\mathrm{x}$ & & & $\mathrm{x}$ & $\mathrm{x}$ & & & \\
\hline & Deferribacter thermophilus & U75602 & 1551 & $\mathrm{x}$ & & & $\mathrm{x}$ & $\mathrm{x}$ & & & \\
\hline & Geovibrio ferrireducens & X95744 & 1542 & $\mathrm{x}$ & & & $\mathrm{x}$ & $\mathrm{x}$ & & & \\
\hline \multirow{3}{*}{ Verrucomicrobia } & Verrucomicrobium spinosum & X90515 & 1489 & $\mathrm{x}$ & & $\mathrm{x}$ & $\mathrm{x}$ & $\mathrm{x}$ & & $\mathrm{x}$ & $\mathrm{x}$ \\
\hline & Hot-spring clone OPB35 & AF027005 & 1492 & $\mathrm{x}$ & & $\mathrm{x}$ & $\mathrm{x}$ & $\mathrm{x}$ & & $\mathrm{x}$ & $\mathrm{x}$ \\
\hline & $\begin{array}{l}\text { Contaminated-aquifer } \\
\text { clone WCHB1-25 }\end{array}$ & AF050559 & 1484 & $\mathrm{x}$ & & $\mathrm{x}$ & $\mathrm{x}$ & $\mathrm{x}$ & & $\mathrm{x}$ & $\mathrm{x}$ \\
\hline \multirow{3}{*}{ Thermus/Deinococcus } & Thermus aquaticus & L09663 & 1470 & $\mathrm{x}$ & & $\mathrm{x}$ & $\mathrm{x}$ & $\mathrm{x}$ & & $\mathrm{x}$ & $\mathrm{x}$ \\
\hline & Meiothermus ruber & C09672 & 1442 & $\mathrm{x}$ & & $\mathrm{x}$ & $\mathrm{x}$ & $\mathrm{x}$ & & $\mathrm{x}$ & $\mathrm{x}$ \\
\hline & Deinococcus radiodurans & M21413 & 1502 & $\mathrm{x}$ & & $\mathrm{x}$ & $\mathrm{x}$ & $\mathrm{x}$ & & $\mathrm{x}$ & $\mathrm{x}$ \\
\hline \multirow[t]{3}{*}{ Thermotogales } & Thermotoga maritima & M21774 & 1562 & $\mathrm{x}$ & & & $\mathrm{x}$ & $\mathrm{x}$ & & & \\
\hline & Fervidobacterium islandicum & M59176 & 1434 & $\mathrm{x}$ & & & $\mathrm{x}$ & $\mathrm{x}$ & & & \\
\hline & Geotoga subterranea & L10659 & 1528 & $\mathrm{x}$ & & & $\mathrm{x}$ & $\mathrm{x}$ & & & \\
\hline \multirow{3}{*}{ Actinobacteria } & Streptomyces coelicolor & X60514 & 1551 & & $\mathrm{x}$ & $\mathrm{x}$ & & & $\mathrm{x}$ & $\mathrm{x}$ & $\mathrm{x}$ \\
\hline & Atopobium minutum & $\mathrm{X} 67145$ & 1452 & & $\mathrm{x}$ & $\mathrm{x}$ & & & $\mathrm{x}$ & $\mathrm{x}$ & $\mathrm{x}$ \\
\hline & Acidimicrobium ferrooxidans & U75647 & 1465 & & $\mathrm{x}$ & $\mathrm{x}$ & & & $\mathrm{x}$ & $\mathrm{x}$ & $\mathrm{x}$ \\
\hline \multirow[t]{3}{*}{ Acidobacteria } & Acidobacterium capsulatum & D26171 & 1418 & & $\mathrm{x}$ & & & & $\mathrm{x}$ & & \\
\hline & Holophaga foetida & X77215 & 1500 & & $\mathrm{x}$ & & & & $\mathrm{x}$ & & \\
\hline & Hot-spring clone OPB3 & AF027004 & 1432 & & $\mathrm{x}$ & & & & $\mathrm{x}$ & & \\
\hline \multirow[t]{3}{*}{ Cytophagales } & Rhodothermus marinus & X77140 & 1543 & & $\mathrm{x}$ & & & & $\mathrm{x}$ & $\mathrm{x}$ & $\mathrm{x}$ \\
\hline & Thermonema lapsum & L11703 & 1490 & & $\mathrm{x}$ & & & & $\mathrm{x}$ & $\mathrm{x}$ & $\mathrm{x}$ \\
\hline & Flavobacterium johnsoniae & M59051 & 1442 & & $\mathrm{x}$ & & & & $\mathrm{x}$ & $\mathrm{x}$ & $\mathrm{x}$ \\
\hline \multirow[t]{3}{*}{ Aquificales } & Aquifex pyrophilus & M83548 & 1564 & & $\mathrm{x}$ & $\mathrm{x}$ & & $\mathrm{x}$ & $\mathrm{x}$ & & $\mathrm{x}$ \\
\hline & Hydrogenobacter acidophilus & D16296 & 1432 & & $\mathrm{x}$ & $\mathrm{x}$ & & $\mathrm{x}$ & $\mathrm{x}$ & & $\mathrm{x}$ \\
\hline & Hot-spring clone OPB13 & AF027098 & 1447 & & $\mathrm{x}$ & $\mathrm{x}$ & & $\mathrm{x}$ & $\mathrm{x}$ & & $\mathrm{x}$ \\
\hline \multirow[t]{3}{*}{ Nitrospira } & Nitrospira marina & X82559 & 1533 & & $\mathrm{x}$ & & & & $\mathrm{x}$ & & \\
\hline & Leptospirillum ferrooxidans & X86776 & 1481 & & $\mathrm{x}$ & & & & $\mathrm{x}$ & & \\
\hline & Magnetobacterium bavaricum & X71836 & 1513 & & $\mathrm{x}$ & & & & $\mathrm{x}$ & & \\
\hline \multirow[t]{3}{*}{$\begin{array}{l}\text { Green non-sulfur } \\
\text { (GNS) }\end{array}$} & $\begin{array}{l}\text { Contaminated aquifer } \\
\text { clone WCHB1-43 }\end{array}$ & AF050564 & 1423 & & & $\mathrm{x}$ & & & & $\mathrm{x}$ & $\mathrm{x}$ \\
\hline & Thermomicrobium roseum & M34115 & 1522 & & & $\mathrm{x}$ & & & & $\mathrm{x}$ & $\mathrm{x}$ \\
\hline & Chloroflexus aurantiacus & M34116 & 1413 & & & $\mathrm{x}$ & & & & $\mathrm{x}$ & $\mathrm{x}$ \\
\hline $\begin{array}{l}\text { Total number of } \\
\text { sequences in each } \\
\text { dataset: }\end{array}$ & & & & 20 & 20 & 20 & 22 & 25 & 22 & 22 & 25 \\
\hline
\end{tabular}

* Ingroups (sequences of primary interest) are indicated in bold.

$\dagger \mathrm{X}$ indicates that the sequence is a member of the dataset.

t The $\alpha$-, $\beta$ - and $\gamma$-Proteobacteria only are represented, as monophyly of the whole division is not always supported $(\delta$ - and $\varepsilon$-subdivision representatives were not included).

recently proposed candidate bacterial divisions, OP9 and OP10 (Hugenholtz et al., 1998a), in the light of a number of new OP9- and OP10-like 16S rDNA sequences identified in the databases. The hypothesis is simple to state: if a specific relationship exists between the OP and OP-like sequences, they will form a monophyletic group under all outgroup conditions.
The hypothesis is tested by using several phylogenetic inference methods on five sets of outgroup sequences with a constant ingroup. If the hypothesis cannot be refuted, the ingroup will be assumed to be monophyletic. However, if one or more datasets divides the ingroup, the hypothesis of monophyly will be refuted and reanalysed when more sequences are available. 


\section{METHODS}

$16 \mathrm{~S}$ rDNA sequence datasets. The $16 \mathrm{~S}$ rDNA sequence data for this study are available through the public databases, under the accession numbers listed in Table 1. Three environmental clone sequences (SBR1039, CH21 and GC55) were determined in this study using methods described previously (Burrell et al., 1998). Sequences were aligned in the ARB database (Ludwig \& Strunk, 1997) and exported using the Lane mask as a filter (Lane, 1991). Datasets contained between 20 and 25 sequences comprising an ingroup (the taxa of primary interest) and five sets of division-level outgroup sequences selected from a total of 11 outgroup divisions (Table 1). Each outgroup division comprised three taxa representing the known phylogenetic breadth of that division to avoid long unbroken branches to outgroups. Of the 40 or so bacterial divisions that have been recognized (Hugenholtz et al., 1998b), 11 were selected for use as possible outgroups for this study (Table 1). They included well-characterized divisions with many cultivated representatives, such as the Proteobacteria and the Actinobacteria, and recently described divisions such as the Acidobacteria and the Verrucomicrobia. Divisions with long branch lengths (e.g. Planctomycetes and OP11) or questionable monophyly (e.g. the low-G $+\mathrm{C}$ Gram-positives; Ludwig \& Schleifer, 1999) were not used as outgroups. Most 16S rDNA sequences used were almost full length $(\geqslant 1400 \mathrm{nt})$, and shorter sequences were selected only occasionally when the lack of full-length sequences necessitated their inclusion.

Phylogenetic analyses. PAUP* for UNIX (test version 4.0d64 written by David L. Swofford) was used for ML, maximumparsimony (MP) and evolutionary-distance (ED) analyses. For ED and ML methods, the general time-reversible (GTR) substitution model was used (Lanave et al., 1984; Rodríguez et al., 1990). The shape parameter $\alpha$ (used for determining the shape of the gamma distribution; Yang, 1994), the rate matrix (R; PAUP* manual) and the proportion of invariable sites $\left(\mathrm{P}_{\text {inv }}\right)$ were estimated simultaneously using $\mathrm{ML}$, as outlined in Fig. 1. Starting with the F81 model (Felsenstein, 1981) without a gamma distribution (Yang, 1994), using the heuristic search function (hsearch), a tree was obtained from

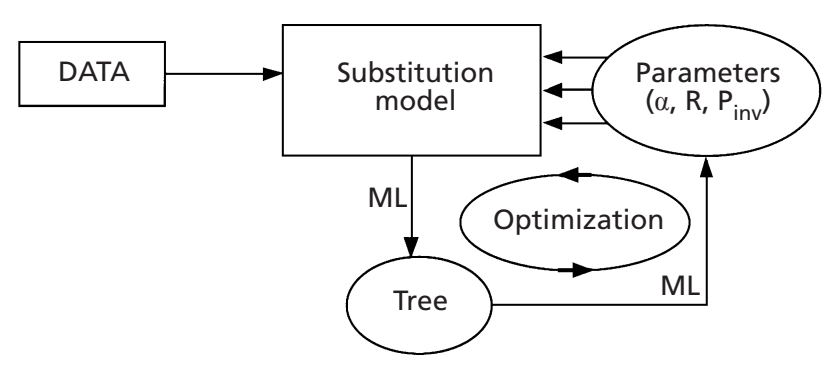

Fig. 1. Procedure for optimization of parameters in PAUP*. ML is used to infer a phylogenetic tree from the data using a specified substitution model. The idea is to optimize the substitution model so that it describes the data accurately with respect to model parameters $\alpha$ (shape parameter), $\mathrm{R}$ (rate matrix) and $P_{\text {inv }}$ (proportion of invariable sites). A tree is obtained from a given model such as F81 and the parameters are estimated from this tree and inserted into the substitution model. A new tree is then calculated and new values for the parameters are estimated. The procedure goes on until the values of the parameters have converged on single values. which $\alpha, R$ and $P_{\text {inv }}$ were estimated simultaneously by optimizing the likelihood for that tree. These estimates were then used to obtain a new tree using hsearch from which new estimates were obtained. The procedure was repeated until the parameter estimates converged on single values. Several distances were used, but only the results from the ML distance, using the GTR substitution model with $\mathrm{P}_{\text {inv }}$ excluded and a gamma distribution, are shown. The optimal criterion minimum evolution for ED methods was used with an option to set negative branch lengths to zero. MP analyses were performed using the default settings and hsearch.

The software program fastDNAml (Felsenstein, 1981; Olsen et al., 1994) version 3.3 for UNIX was used for additional $\mathrm{ML}$ analyses. The transition/transversion ratio $(\mathrm{T})$ value that best described the data was found by optimizing the likelihood function with respect to $T$, starting from $T=1 \cdot 0$ in steps of $0 \cdot 1$ until an optimum was found $(1 \cdot 0,1 \cdot 1,1 \cdot 2$, etc.). The auxiliary program DNArates version 1.0.3 (G. J. Olsen, S. Pracht and R. Overbeek, unpublished; available at http:// geta.life.uiuc.edu/ gary/programs/DNArates.html) was used to calculate rate categories and incorporated into fastDNAml to correct for rate heterogeneity in the data. Nine rate categories were selected.

In order to assess branch support, bootstrap resampling was performed. For MP and ED methods, 2000 replications were used to obtain reasonable accuracy in the bootstrap proportion (BP) values (Hedges, 1992). When using ratecorrected ML methods in fastDNAml, the number of replications was restricted to 100 to save computation time. No bootstrap analysis using ML as optimal criterion was performed in PAUP*. The confidence interval available for branch lengths in fastDNAml was also used as a measure of support. If branch lengths obtained by ML methods had a confidence interval including only positive numbers, the branch was considered to be supported (at a level of $P<0 \cdot 01)$.

\section{RESULTS}

A bacterial division is defined as a lineage consisting of two or more $16 \mathrm{~S}$ rRNA sequences that is reproducibly monophyletic and unaffiliated to all other division-

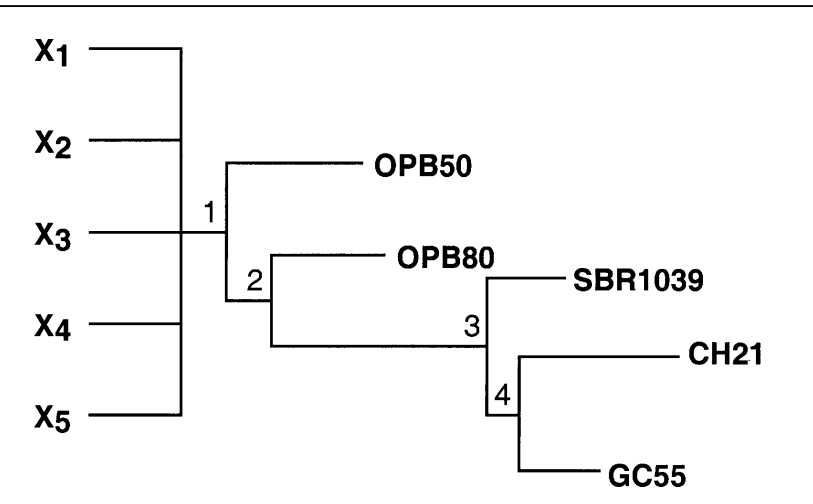

Fig. 2. Schematic representation of the OP10 datasets studied. The ingroup is shown to the right of the figure and outgroups are represented as $X_{1}-X_{5}$. Each $X$ represents one division comprising three sequences, according to Table 1 . The ingroup nodes are numbered $1-4$. 
Table 2 Summary of the results from phylogenetic analyses of the OP10 and OP9 datasets

\begin{tabular}{|c|c|c|c|c|c|c|c|c|c|}
\hline \multirow[t]{2}{*}{ Dataset } & \multirow[t]{2}{*}{ Method $\dagger$} & \multirow[t]{2}{*}{ Software } & \multicolumn{3}{|c|}{ Inference parameters } & \multicolumn{4}{|c|}{ Node } \\
\hline & & & NST & $\mathbf{R C} \S$ & $\mathbf{P}_{\mathrm{inv}} \|$ & 1 & 2 & 3 & 4 \\
\hline \multirow[t]{5}{*}{ OP10A } & ML & fastDNAml & $2(\mathrm{~T}=1 \cdot 3)$ & DNArates & 0 & + & + & + & + \\
\hline & ML & PAUP* & 6 & gamma $(\alpha=0.35)$ & $0 \cdot 36$ & $\mathrm{R}$ & $\mathrm{R}$ & $\mathrm{R}$ & $\mathrm{R}$ \\
\hline & MLboot & fastDNAml & $2(\mathrm{~T}=1 \cdot 3)$ & DNArates & 0 & 100 & 95 & 100 & 61 \\
\hline & MPboot & PAUP* & 1 & None & 0 & 85 & 71 & 100 & 92 \\
\hline & EDboot & PAUP* & 6 & gamma $(\alpha=0.35)$ & 0 & 99 & 54 & 100 & 68 \\
\hline \multirow[t]{5}{*}{ OP10B } & ML & fastDNAml & $2(\mathrm{~T}=1 \cdot 2)$ & DNArates & 0 & + & + & + & + \\
\hline & ML & PAUP* & 6 & gamma $(\alpha=0.87)$ & $0 \cdot 35$ & $\mathrm{R}$ & $\mathrm{R}$ & $\mathrm{R}$ & $\mathrm{R}$ \\
\hline & MLboot & fastDNAml & $2(\mathrm{~T}=1 \cdot 2)$ & DNArates & 0 & 100 & 90 & 100 & 64 \\
\hline & MPboot & PAUP* & 1 & None & 0 & 100 & 78 & 100 & 93 \\
\hline & EDboot & PAUP* & 6 & gamma $(\alpha=0.87)$ & 0 & 100 & $<50$ & 100 & $<50$ \\
\hline \multirow[t]{5}{*}{ OP10C } & ML & fastDNAml & $2(\mathrm{~T}=1 \cdot 1)$ & DNArates & 0 & + & + & + & + \\
\hline & ML & PAUP* & 6 & gamma $(\alpha=0.65)$ & $0 \cdot 25$ & $\mathrm{R}$ & $\mathrm{R}$ & $\mathrm{R}$ & $\mathrm{R}$ \\
\hline & MLboot & fastDNAml & $2(\mathrm{~T}=1 \cdot 1)$ & DNArates & 0 & 100 & 97 & 100 & 80 \\
\hline & MPboot & PAUP* & 1 & None & 0 & 99 & 89 & 100 & 95 \\
\hline & EDboot & PAUP* & 6 & gamma $(\alpha=0.65)$ & 0 & 97 & $<50$ & 100 & 62 \\
\hline \multirow[t]{5}{*}{ OP9A } & ML & fastDNAml & $2(\mathrm{~T}=1 \cdot 2)$ & DNArates & 0 & + & + & + & \\
\hline & ML & PAUP* & 6 & gamma $(\alpha=0.79)$ & $0 \cdot 37$ & $\mathrm{R}$ & $\mathrm{R}$ & $\mathrm{R}$ & \\
\hline & MLboot & fastDNAml & $2(\mathrm{~T}=1 \cdot 2)$ & DNArates & 0 & 94 & 100 & 100 & \\
\hline & MPboot & PAUP* & 1 & None & 0 & 86 & 100 & 89 & \\
\hline & EDboot & PAUP* & 6 & gamma $(\alpha=0.79)$ & 0 & 78 & 100 & 99 & \\
\hline \multirow[t]{5}{*}{ OP9A2 } & ML & fastDNAml & $2(\mathrm{~T}=1 \cdot 2)$ & DNArates & 0 & + & + & + & \\
\hline & ML & PAUP* & 6 & gamma $(\alpha=0.79)$ & $0 \cdot 35$ & $\mathrm{R}$ & $\mathrm{R}$ & $\mathrm{R}$ & \\
\hline & MLboot & fastDNAml & $2(\mathrm{~T}=1 \cdot 2)$ & DNArates & 0 & 92 & 100 & 100 & \\
\hline & MPboot & PAUP* & 1 & None & 0 & 81 & 100 & 92 & \\
\hline & EDboot & PAUP* & 6 & gamma $(\alpha=0.79)$ & 0 & 87 & 100 & 100 & \\
\hline \multirow[t]{5}{*}{ OP9B } & ML & fastDNAml & $2(\mathrm{~T}=1 \cdot 3)$ & DNArates & 0 & NR & + & + & \\
\hline & ML & PAUP* & 6 & gamma $(\alpha=0.80)$ & $0 \cdot 35$ & NR & $\mathrm{R}$ & $\mathrm{R}$ & \\
\hline & MLboot & fastDNAml & $2(\mathrm{~T}=1 \cdot 3)$ & DNArates & 0 & NR & 100 & 100 & \\
\hline & MPboot & PAUP* & 1 & None & 0 & 65 & 100 & 88 & \\
\hline & EDboot & PAUP* & 6 & gamma $(\alpha=0.80)$ & 0 & 79 & 100 & 100 & \\
\hline \multirow[t]{5}{*}{ OP9C } & ML & fastDNAml & $2(\mathrm{~T}=1 \cdot 2)$ & DNArates & 0 & + & + & + & \\
\hline & ML & PAUP* & 6 & gamma $(\alpha=0.61)$ & $0 \cdot 23$ & $\mathrm{R}$ & $\mathrm{R}$ & $\mathrm{R}$ & \\
\hline & MLboot & fastDNAml & $2(\mathrm{~T}=1 \cdot 2)$ & DNArates & 0 & 91 & 100 & 100 & \\
\hline & MPboot & PAUP* & 1 & None & 0 & 94 & 100 & 87 & \\
\hline & EDboot & PAUP* & 6 & gamma $(\alpha=0.61)$ & 0 & 98 & 100 & 100 & \\
\hline \multirow[t]{5}{*}{ OP9C2 } & ML & fastDNAml & $2(\mathrm{~T}=1 \cdot 2)$ & DNArates & 0 & + & + & + & \\
\hline & ML & PAUP* & 6 & gamma $(\alpha=0.89)$ & $0 \cdot 28$ & $\mathrm{R}$ & $\mathrm{R}$ & $\mathrm{R}$ & \\
\hline & MLboot & fastDNAml & $2(\mathrm{~T}=1 \cdot 2)$ & DNArates & 0 & 87 & 100 & 100 & \\
\hline & MPboot & PAUP* & 1 & None & 0 & 74 & 100 & 95 & \\
\hline & EDboot & PAUP* & 6 & gamma $(\alpha=0.89)$ & 0 & 94 & 100 & 100 & \\
\hline
\end{tabular}

$\dagger$ ML, Maximum-likelihood; MLboot, ML bootstrap using 100 replications; MPboot, MP bootstrap using 2000 replications; EDboot, ED bootstrap using 2000 replications. All distances are ML distances.

$\ddagger$ Number of substitution types; 1 indicates equal rates; for 2 types, the transition/transversion ratio (T) is estimated (in parentheses); for 6 types, the GTR substitution model was used.

$\S$ Rate correction applied; DNArates classifies each alignment position into one of nine rate categories by optimizing the likelihood function at that position; gamma, gamma distribution calculated using the shape parameter $\alpha$ (estimated value in parentheses) and divided into four rate categories.

\| Proportion of invariable sites; non-zero values were estimated in PAUP*.

$\uparrow$ Interior nodes as numbered in Figs 2 (OP10 datasets) and 3 (OP9 datasets). +, Positive branch length according to the Kishino-Hasegawa confidence interval at $P<0.01$; R, resolved as an interior node; NR, not resolved as an interior node. Numbers are bootstrap proportion (BP) values. 
level relatedness groups that constitute the bacterial domain (Hugenholtz et al., 1998b). Two groups of $16 \mathrm{~S}$ rDNA clone sequences apparently affiliated to novel bacterial divisions OP10 and OP9 (Hugenholtz et al., 1998b) have been used as case studies to resolve ambiguous evolutionary relationships at the division level. The aim of the present study was to determine whether these OP-like groups are monophyletic with the OP divisions to the exclusion of all other bacterial divisions. For each of the groups, the hypothesis of monophyly has been tested using at least three different datasets with ingroups (OP and OP-like sequences) kept constant and division-level outgroups selected from full-length sequences in the ARB database (Ludwig \& Strunk, 1997). Multiple representatives of outgroup divisions were used to avoid long unbroken branch lengths arising from lack of close relatives to the representative. A complete listing of sequences used in the case studies is presented in Table 1, including the OP and OP-like ingroup sequences. ML was the principal inference method used for the phylogenetic analyses of the datasets and included corrections for rate heterogeneity. Substitution model parameters used in the inference methods were optimized as outlined in Fig. 1. Statistical support for inferred topologies was estimated using the KishinoHasegawa confidence interval available in fastDNAml (Kishino \& Hasegawa, 1989) and bootstrap resampling. Where computationally possible (i.e. ED, MP analyses), 2000 replications were used to reduce the standard deviation (Hedges, 1992).

\section{OP10 case study}

The phylogenetic relationships of OP10 sequences (OPB50 and OPB80) obtained from a hot spring (Hugenholtz et al., 1998a) and three OP10-like sequences (SBR1039, CH21 and GC55) obtained from activated sludges were studied (Table 1). To determine the effect of outgroup bias on ingroup monophyly, three datasets with varying outgroup composition were created and analysed (Table 1), shown schematically in Fig. 2. All analyses of the three datasets support the monophyly of the ingroup, i.e. interior node 1 was consistently resolved (Fig. 2, Table 2). The conclusion is that the sludge sequences (SBR1039, CH21 and GC55) are members of candidate division OP10.

\section{OP9 case study}

The relationships of four OP9-like sequences from a benzene-mineralizing consortium (SB-15, SB-45; Phelps et al., 1998) and deep-sea sediment (JTB138, JTB243; Li et al., 1999) to OP9 sequences were studied (Table 1). It was necessary to use partial length sequences (TUG14, OPB72) due to the limited representation of the OP9 division at the time of analysis. Initially, three datasets (OP9A, OP9B and OP9C) were constructed using similar combinations of outgroups selected from the same outgroup representatives used

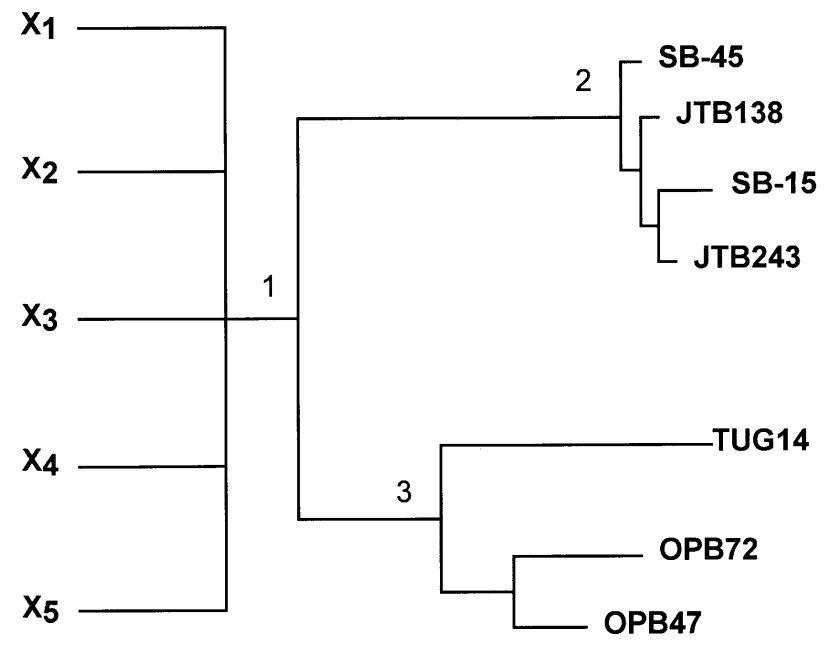

Fig. 3. Schematic representation of the OP9 datasets studied. The ingroup is shown to the right of the figure and outgroups are represented as $X_{1}-X_{5}$. Each $X$ represents one division comprising three sequences, according to Table 1 . The ingroup nodes are numbered $1-3$.

in the OP10 case study (Table 1), shown schematically in Fig. 3. As for the previous case study, support for node 1 (Fig. 3) would establish the monophyly of the ingroup. All internal nodes are not numbered explicitly, since they are not necessary for establishing ingroup monophyly. Rate-corrected ML analyses (Table 2) indicated support for node 1 for two datasets (OP9A and OP9C) but not for the third (OP9B). Bootstrap analyses of ML trees for datasets OP9A and OP9C using 100 replications supported ingroup monophyly, with BP values of $>90 \%$ (Table 2). However, the ingroup was not monophyletic in dataset OP9B using ML analyses (node 1 in Fig. 3 was not resolved as an interior node). Instead, the OP9-like sequences clustered with the division Aquificales. The node connecting the cluster (OP9-like-Aquificales) had a BP of $89 \%$ (data not shown), which is often considered as statistically supported (e.g. Lake \& Moore, 1998). This case study demonstrates how outgroup composition can have critical effects on phylogenetic inference.

Sequences from the outgroup division Aquificales were included only in dataset OP9B and not in datasets OP9A and OP9C. In order to determine whether the division Aquificales was responsible for the break-up of the ingroup, two additional datasets (OP9A2 and OP9C2) were analysed. These additional datasets included the outgroups of OP9A and OP9C, respectively, and the sequences from the division Aquificales (Table 1). All analyses of both OP9A2 and OP9C2 supported ingroup monophyly, and the Aquificales-OP9-like sequence cluster did not occur.

The division Aquificales has recently been suggested to branch artefactually deeply in the bacterial domain because of long-branch attraction (LBA) (Philippe \& 
Laurent, 1998), and the branch leading to the OP9-like sequences is relatively long (Fig. 3; node 2). Therefore, the association of the OP9-like sequences with the division Aquificales may be an LBA artefact. This obstacle prevents strict conclusions being drawn from the analysis; however, the OP9-like sequences will be considered unaffiliated to OP9 until proven otherwise, according to the initial hypothesis. Additional sequences dividing the branch length to node 2 (Fig. 3) should help to resolve the issue.

\section{DISCUSSION}

There are many different steps that are taken to optimize the accuracy of phylogenetic trees. It is important to be aware of the pitfalls that may harm the estimate and lead to inconsistent tree topologies. Some of these are: (i) using too short sequences, (ii) badly aligned sequences, (iii) high noise level (non-filtered data), (iv) using inappropriate phylogenetic models and (v) badly selected reference organisms. Although we have chiefly addressed points (iv) and (v) in the present study, points (i)-(iii) are not insignificant.

Different attempts have been made to assess the number of nucleotides needed to obtain a sufficient signal from the data (Hillis et al., 1994; Lecointre et al., 1994; Zharkikh \& Li, 1992). There is no one answer to how many nucleotides to use in a generic dataset. However, for rRNA datasets, a qualitative observation is that 5S rRNA $(\sim 120 \mathrm{nt})$ is too small to resolve phylogenetic relationships beyond the species/genus level, whereas 16S rRNA ( $\sim 1550 \mathrm{nt})$ is generally thought to be adequate to resolve relationships at least to the division (phylum) level (Amann et al., 1995; Ludwig \& Schleifer, 1999). The 16S rRNA secondary structure can be used for alignment purposes when identifying homologous sites (e.g. Gutell, 1996). The ARB editor uses the secondary structure of Escherichia coli $16 \mathrm{~S}$ rRNA to aid in alignment (Ludwig \& Strunk, 1997). Nucleotide positions in the sequence alignment can be homologous but phylogenetically uninformative (e.g. rapidly evolving sites). These sites contribute to noise that may affect the ability to obtain accurate phylogenetic estimates. Noise in data can be removed by using different filters, for example the Lane mask for bacterial 16S rRNA datasets (Lane, 1991).

When nothing is known about the evolution of sequences, it is not possible to state that one phylogenetic model is better than another. However, the sequence evolution of $16 \mathrm{~S}$ rDNA is not entirely unknown: for example, sites in sequences are recognized to have evolved at different rates due to functional constraints (Woese, 1987). Since most inference methods assume equal rates, it is important to correct for site-to-site rate variation. There are different methods available to model rate heterogeneity. The simplest is to use a model that assumes that there is a proportion of sites that are incapable of accepting substitutions ( $\mathrm{P}_{\text {inv }}$; Swofford et al., 1996). In this study, we estimated an optimal $\mathrm{P}_{\text {inv }}$ for a given dataset by an iterative method (Fig. 1) using PAUP*. A more complex way is to divide the dataset into rate categories, using either a continuous (gamma) distribution or by assigning a rate to each site by optimizing the likelihood function at that site (Swofford et al., 1996). A steep decline in the negative log likelihood value was observed for all datasets as rate-heterogeneity was taken into account when studying the likelihood of a tree with respect to different parameters (e.g. Huelsenbeck \& Crandall, 1997). In conclusion, we suggest that all phylogenetic analyses using 16S rDNA data with ED and ML methods should include some correction for rate-heterogeneity.

Outgroups in phylogenetic analyses are often selected on the basis of a close but distinct relationship to the ingroup in order to avoid the LBA artefact of ingroup sequences to distantly related outgroup sequences (Philippe \& Laurent, 1998). However, the majority of bacterial divisions do not have clearly identifiable sister divisions that could act as outgroups, because the bacterial domain has a star topology (Hugenholtz et al., 1998b; Swofford et al., 1996), i.e. an unresolved division-level branching order. One way to bypass this problem is to include all available outgroups or at least a large number of outgroups ( $>200$; Hillis, 1996) in the analysis. This approach is possible using ED or MP inference methods, but is not feasible with ML due to current computation limits on very large datasets. In most studies of microbial phylogeny published to date, only one dataset is analysed, rarely comprising more than 50 sequences regardless of inference method. This study clearly demonstrates that a single set of outgroups in a small dataset may be insufficient to draw conclusions about the monophyly of an ingroup. Therefore, the presented testing of multiple outgroup divisions using relatively small datasets $(<50$ sequences) to establish the monophyly of an ingroup division may be a useful approach to avoid incorrect or misleading phylogenetic conclusions.

\section{ACKNOWLEDGEMENTS}

We thank Nick Campbell for many useful discussions on the manuscript and Gene Tyson and Paul Burrell for fully sequencing clones SBR1039, CH21 and GC55. P.H. is funded by the CRC for Waste Management and Pollution Control Ltd, a centre established and supported under the Australian Government's Cooperative Research Centres Program.

\section{REFERENCES}

Adachi, J. \& Hasegawa, M. (1995). Phylogeny of whales: dependence of the inference on species sampling. Mol Biol Evol 12, 177-179.

Amann, R. I., Ludwig, W. \& Schleifer, K. H. (1995). Phylogenetic identification and in situ detection of individual microbial cells without cultivation. Microbiol Rev 59, 143-169.

Benson, D. A., Boguski, M. S., Lipman, D. J., Ostell, J., Ouellette, B. F. F., Rapp, B. A. \& Wheeler, D. L. (1999). GenBank. Nucleic Acids Res 27, 12-17. 
Burrell, P. C., Keller, J. \& Blackall, L. L. (1998). Microbiology of a nitrite-oxidizing bioreactor. Appl Environ Microbiol 64, 1878 1883.

Doolittle, W. F. (1999). Phylogenetic classification and the universal tree. Science 284, 2124-2129.

Felsenstein, J. (1981). Evolutionary trees from DNA sequences: a maximum likelihood approach. J Mol Evol 17, 368-376.

Gutell, R. R. (1996). Comparative sequence analysis and the structure of $16 \mathrm{~S}$ and $23 \mathrm{~S}$ rRNA. In Ribosomal RNA. Structure, Evolution, Processing, and Function in Protein Synthesis, pp. 111-128. Edited by R. A. Zimmerman \& A. E. Dahlberg. Boca Raton, FL: CRC Press.

Hedges, S. B. (1992). The number of replications needed for accurate estimation of the bootstrap $\mathrm{P}$ value in phylogenetic studies. Mol Biol Evol 9, 366-369.

Hillis, D. M. (1996). Inferring complex phylogenies. Nature 383, 130-131.

Hillis, D. M., Huelsenbeck, J. P. \& Cunningham, C. W. (1994). Application and accuracy of molecular phylogenies. Science 264, 671-677.

Huelsenbeck, J. P. \& Crandall, K. A. (1997). Phylogeny estimation and hypothesis testing using maximum likelihood. Annu Rev Ecol Syst 28, 437-466.

Hugenholtz, P., Pitulle, C., Hershberger, K. L. \& Pace, N. R. (1998a). Novel division level bacterial diversity in a Yellowstone hot spring. J Bacteriol 180, 366-376.

Hugenholtz, P., Goebel, B. M. \& Pace, N. R. (1998b). Impact of culture-independent studies on the emerging phylogenetic view of bacterial diversity. J Bacteriol 180, 4765-4774.

Kishino, H. \& Hasegawa, M. (1989). Evaluation of the maximum likelihood estimate of the evolutionary tree topologies from DNA sequence data, and the branching order in hominoidea. $J$ Mol Evol 29, 170-179.

Lake, J. A. \& Moore, J. E. (1998). Phylogenetic analysis and comparative genomics. Trends Biotechnol Suppl. S, 22-23.

Lanave, C., Preparata, G., Saccone, C. \& Serio, G. (1984). A new method for calculating evolutionary substitution rates. $J \mathrm{Mol}$ Evol 20, 86-93.

Lane, D. J. (1991). 16S/23S rRNA sequencing. In Nucleic Acid Techniques in Bacterial Systematics, pp. 115-175. Edited by E. Stackebrandt \& M. Goodfellow. New York: Wiley.

Lecointre, G., Philippe, H., Lanh van Le, H. \& Le Guyader, H. (1994). How many nucleotides are required to resolve a phylogenetic problem? The use of a new statistical method applicable to available sequences. Mol Phylogenet Evol 3, 292-309.
Li, L., Kato, C. \& Horikoshi, K. (1999). Microbial diversity in sediments collected from the deepest cold-seep area, the Japan Trench. Mar Biotechnol 1, 391-400.

Ludwig, W. \& Schleifer, K.-H. (1999). Phylogeny of bacteria beyond the 16S rRNA standard. ASM News 65, 752-757.

Ludwig, W. \& Strunk, O. (1997). ARB, a software environment for sequence data. http://www.mikro.biologie.tu-muenchen.de/

Olsen, G. J., Matsuda, H., Hagstrom, R. \& Overbeek, R. (1994). fastDNAml: a tool for construction of phylogenetic trees of DNA sequences using maximum likelihood. Comput Appl Biosci 10, 41-48.

Pennisi, E. (1998). Genome data shake tree of life. Science 280, 672-674.

Phelps, C. D., Kerkhof, L. J. \& Young, L. Y. (1998). Molecular characterization of a sulfate-reducing consortium which mineralizes benzene. FEMS Microbiol Ecol 27, 269-279.

Philippe, H. \& Laurent, J. (1998). How good are deep phylogenetic trees? Curr Opin Genet Dev 8, 616-623.

Rodríguez, F., Oliver, J. L., Marín, A. \& Medina, J. R. (1990). The general stochastic model of nucleotide substitution. $J$ Theor Biol 142, 485-501.

Smith, A. B. (1994). Rooting molecular trees-problems and strategies. Biol J Linn Soc 51, 279-292.

Stackebrandt, E. \& Ludwig, W. (1994). The importance of using outgroup reference organisms in phylogenetic studies-the Atopobium case. Syst Appl Microbiol 17, 39-43.

Stoesser, G., Tuli, M. A., Lopez, R. \& Sterk, P. (1999). The EMBL nucleotide sequence database. Nucleic Acids Res 27, 18-24.

Sugawara, H., Miyazaki, S., Gojobori, T. \& Tateno, Y. (1999). DNA Data Bank of Japan dealing with large-scale data submission. Nucleic Acids Res 27, 25-28.

Swofford, D. L., Olsen, G. J., Waddell, P. J. \& Hillis, D. M. (1996). Phylogenetic inference. In Molecular Systematics, pp. 407-514. Edited by D. M. Hillis, C. Moritz \& B. K. Mable. Sunderland, MA: Sinauer.

Woese, C. R. (1987). Bacterial evolution. Microbiol Rev 51, 221-271.

Yang, Z. H. (1994). Maximum likelihood phylogenetic estimation from DNA sequences with variable rates over sites: approximate methods. J Mol Evol 39, 306-314.

Zharkikh, A. \& Li, W.-H. (1992). Statistical properties of bootstrap estimation of phylogenetic variability from nucleotide sequences. I. Four taxa with a molecular clock. Mol Biol Evol 9, $1119-1147$. 